\title{
Introducción del paradigma higiénico sanitario en Chile (1870-1925): discursos y prácticas*/
}

\author{
Introduction of the Sanitary Hygienic Paradigm \\ in Chile (1870-1925): Discourses and Practices
}

\author{
Inmaculada Simón Ruiz \\ ORCID iD: http://orcid.org/0000-0001-5820-2930 \\ Raúl Sánchez Andaur \\ ORCID iD: http://orcid.org/0000-0003-4501-2702 \\ Universidad Autónoma de Chile
}

Presentamos un análisis del proceso de introducción y difusión del paradigma higiénico sanitario en Chile en la transición del siglo XIX al XX. Las fuentes principales son legislación y prensa, con el fin de detectar la introducción del discurso, su reproducción y las principales resistencias que encuentra en el proceso de puesta en práctica. Para rescatar la relación entre higienismo y cuestión social, dedicaremos mayor atención a la prensa obrera, considerada portavoz de los trabajadores y de los sectores marginales.

Palabras Clave: Higienismo; Discurso; Aculturación; Ambientalismo; Darwinismo Social; Congresos Internacionales.

This paper presents an analysis of the process of introduction and diffusion of the sanitary hygienic paradigm in Chile in the transition from the 19th to the 20th Century. The sources under the study include the official legislation documents and the press to identify the discourse introduction, its public reproduction and the main difficulties of its realization. We are interested in the relationship between the higienism and the social issues. In order to do so, we will focus on the working press, considered to be the leading voice of the workers and marginal sectors.

KeYwords: Hygienic Paradigm; Speech; Acculturation; Environmentalism; Social Darwinism; International Congresses.

Copyright: (C) 2017 CSIC. Este es un artículo de acceso abierto distribuido bajo los términos de una licencia de uso y distribución Creative Commons Attribution (CC-by) España 3.0.

* Investigación realizada en el marco del proyecto FONDECYT Regular n. ${ }^{\circ} 1140292$, titulado «Transformaciones políticas y socio-ambientales derivadas del cambio en el paradigma higiénico sanitario. Modernización del sistema de aguas en Chile a finales del siglo XIX: los casos de Valparaíso y Talca», financiado por el CONICYT. Agradecemos a los evaluadores sus recomendaciones en la revisión de este artículo. 


\section{Introducción}

Analizamos aquí el proceso de introducción y difusión del paradigma higiénico sanitario en Chile entre 1870 y 1925. Los ejes temporales corresponden a la organización de la Sociedad Médica de Santiago y la promulgación del Código Sanitario, que transforma los principios del paradigma en norma jurídica, tiempo en que se asumen los mismos como norma. Dicho período coincide con el del tránsito del Estado liberal decimonónico al social del siglo XX. En estas páginas nos ocuparemos de algunos aspectos generales en torno a la difusión del discurso desde la institucionalidad, para acercarnos después a la recepción del mismo, haciendo referencia a las oposiciones que encontró tanto dentro como fuera del sistema, así como a la acogida que tuvo entre las agrupaciones obreras, el sector más vulnerable en la cuestión higiénico sanitaria. Toda la problemática urbana y de salud vinculada al higienismo (abastecimiento de agua, vivienda, salud, alcoholismo...) estuvo íntimamente relacionada con la denominada «cuestión social» en el período que nos ocupa, siendo la preocupación constante de los reformistas decimonónicos europeos y americanos.

Partimos de la hipótesis de que en esta materia hubo un gran divorcio entre las ideas y las prácticas, puesto que si bien los poderes públicos aceptaron la teoría y ayudaron a difundirla, no apoyaron con la misma contundencia las transformaciones necesarias para su implementación, como denunciaron con frecuencia higienistas de la talla de Pedro Lautaro Ferrer o Federico Puga Borne. En esta tibieza a la hora de aplicar la normativa jugó un papel importante la oposición presentada, de manera más o menos abierta, por una serie heterogénea de actores (políticos, periodistas, líderes de organizaciones obreras, empresarios, rentistas, propietarios de viviendas, etc.), como señalaremos a lo largo del texto. Por ello, las reformas se aplicaron de manera parcial, lo que incidió en que el acceso a la salud y a la higiene se convirtiera en un instrumento más en el ejercicio de poder, así como en una manifestación de segregación social, afectando principalmente a los barrios más marginales de las ciudades.

La metodología se basa en el trabajo con fuentes para identificar los postulados del higienismo, a sus impulsores en Chile y a las principales instituciones relacionadas, para después proceder a la revisión del discurso emitido desde las mismas, contextualizándolo dentro del panorama internacional. Para acercarnos a la difícil cuestión de identificar la introducción del discurso y sus resistencias fuera del ámbito de la medicina, revisamos 
publicaciones no especializadas con el fin de detectar las referencias al paradigma y cómo se produce la interpretación del discurso (asimilación y oposición) por parte de los distintos actores involucrados.

Comenzaremos abordando el concepto de higienismo y su relación con el agua y la salud y cómo fue planteado por sus principales publicistas. En este apartado veremos la internacionalización del paradigma a través de la participación de los higienistas en conferencias internacionales en las que se discutieron y establecieron las pautas de conducta para su implementación. Este heterogéneo grupo de intelectuales formó parte de una «nebulosa reformista ${ }^{1}$ compuesta por médicos, funcionarios públicos, ingenieros sanitarios, contratistas, etc. implicados en una idea común: transformar las condiciones higiénico sanitarias de las ciudades para modificar, a su vez, la vida de sus ciudadanos en aras de la modernización y la agilidad en las relaciones de intercambio de bienes y personas en el mercado global.

No obstante, la emisión de leyes y la creación de instituciones no fueron suficientes para la implementación de los cambios. Las resistencias de toda índole impedían que los tan anhelados cambios se llevaran a cabo de forma expedita y, con frecuencia, se culpaba a los sectores populares de ser los responsables. Durante el proceso de difusión del discurso, los voceros de la cuestión social insistieron en relacionar las condiciones higiénicas con la pobreza y la marginación, e incluso con la miseria moral y la degeneración de la raza. La persistencia de la supuesta relación entre falta de higiene y pobreza, entre ausencia de salud y miseria moral de los habitantes de los sectores más marginales de las grandes ciudades, llegó a convertirse en un lugar común. Las «costumbres» y los «hábitos sociales» de los trabajadores eran denunciados, con frecuencia, como un obstáculo para la implementación de las propuestas reformistas. Por ello, estos pusieron sus esperanzas en la educación como vía de penetración más efectiva. En un segundo apartado veremos cuáles fueron los principales lineamientos de esta política educativa y los diversos actores que la hicieron posible, entre ellos la prensa obrera. Por mediación de la prensa obrera se fue produciendo la apropiación del discurso, lo que supuso el aceleramiento del proceso de interiorización social del mismo entre la intelligentsia obrera, porque sus voceros se convirtieron en

1 Topalov, 2004. Este heterogéneo grupo estaba conformado por médicos, abogados, profesores, periodistas y empresarios, a los que algunos historiadores (como Juan Carlos Yáñez, 2008) se resisten a denominar «intelectuales». Utilizaremos aquí la denominación de publicistas o de «nebulosa reformista», así como la de intelligentsia médica u obrera, cuando hagamos alusión a sus principales voceros. 
difusores, constituyéndose a su vez en agentes que actuaron a favor de la consolidación de las nuevas prácticas higiénico sanitarias y que a la larga terminaron actuando como un mecanismo más de control social.

En un tercer apartado, analizamos algunas de las resistencias que se presentaron al cumplimiento de las leyes y de las disposiciones emanadas de higienistas y reformistas. Estas no vendrán, precisamente, de los sectores populares sino del lobby conservador que, amparado en el laissez faire, consideraba una intromisión en las libertades individuales cualquier intervención en materia de salud, higiene y trabajo. Este grupo se formará principalmente de empresarios y propietarios de viviendas, que veían amenazadas sus fuentes de ingresos con la introducción de la educación obligatoria, los calendarios de vacunación, las reformas y las demoliciones de los complejos de viviendas de los que obtenían pingües beneficios. Sus representantes en el congreso ralentizaron al máximo los cambios en una labor continuada durante décadas, hasta que terminaron siendo derrotados por el advenimiento del Estado social en Chile.

Otro tipo de resistencia vino desde los sectores populares. En las grandes ciudades chilenas ocurrió algo similar a lo que señala Topalov para otras capitales en las que ciertos sectores obreros se organizaron no para resistir las reformas, sino para adoptarlas y adaptarlas a sus propios intereses al margen de las instituciones del Estado: «Los obreros que tienen un trabajo más fijo y unos ingresos más elevados y regulares comienzan a emigrar hacia los suburbios, se organizan en sociedades mutuas de ahorro y recurren a la autoconstrucción: estos métodos permiten mantener las solidaridades del barrio de origen o de oficio y proporcionan, además, una vivienda propia de la que nadie podrá pedirles cuentas». ${ }^{2}$

En esta línea, destacamos la labor de la Industrial Workers of The World (IWW) que en materia de salud apostó por la autogestión a través de la creación de su propio policlínico en el que se atendía a los trabajadores por muy módicos precios.

Para finalizar, una vez analizado el proceso de institucionalizacióndifusión y las resistencias al paradigma, presentamos algunas consideraciones en torno a la transformación del Estado liberal republicano en el Estado social y el papel que higienistas y reformistas tuvieron en dicho cambio que significó, en definitiva, el fin del sistema oligárquico en Chile como ocurrió en el resto de América Latina.

2 Topalov, 2004, 50. 


\section{Internacionalización e institucionalización del paradigma en Chile}

Desde el siglo XVIII los conocimientos aceptados sobre higiene y enfermedad se fueron transformando desde el higienismo hasta la revolución producida por los avances en microbiología en la década de 1880. Los nuevos hallazgos vinieron a sustituir a las antiguas teorías miasmáticas que relacionaban la enfermedad con el ambiente, si bien reforzaron la idea de que la higiene y la profilaxis eran los mecanismos para evitar la proliferación de las bacterias y, en su caso, prevenir las enfermedades y el contagio. Si el paradigma ecológico defendía que el contagio provenía de las condiciones ambientales (aire malsano, agua estancada, etc.), el bacteriológico puso en evidencia que los elementos contaminantes eran las bacterias, que al ser ingeridas, generalmente a través del agua, producían la enfermedad. Así, al detectar exactamente de dónde venía el mal se facilitaba la posibilidad de erradicarlo, evitándolo. Fue entonces cuando los hospitales dejaron de ser aquellos lugares a los que se llegaba a morir para convertirse en espacios de recuperación de la salud. Los nuevos saberes relacionaron higiene con salud y salud con vida y, por ende, el conocimiento quedó vinculado al poder de decisión sobre la vida y la muerte de las personas, dependiendo de su acceso o no al sistema higiénico sanitario, promovido desde las instituciones a instancias de los especialistas en la materia. Supuso esto, por tanto, un cambio en cuanto a la percepción de la salud y del papel del Estado en ella. Supuso también el fortalecimiento de algunas profesiones como la de médico o ingeniero sanitario y supuso, al fin, la generación de un gran cambio cultural que afectó a las costumbres y a los hábitos en materia, no solo de higiene y medicina, sino de alimentación, ocio, etc.

El higienismo evoluciona apoyado por los descubrimientos científicos y por el afán por obtener una sociedad más sana y, por ende, más productiva, y se transforma en un campo de la medicina en el que se unirán la preocupación por la salud pública con el esfuerzo por entender el origen de las enfermedades y de las epidemias y también la necesidad de mejorar las condiciones de vida de las personas y de las sociedades. Según este esquema, las ciudades comenzaron a ser tratadas también con estas pautas y se transformaron adoptando modelos más «higiénicos» siguiendo el modelo de Haussman en París. En Chile esta labor dará sus pasos iniciales en ciudades como Santiago o Valparaíso en la década de los 70 y se verá reforzada, más adelante, en torno a la celebración del primer centenario de la independencia en la mayoría de las ciudades. 
Bajo este paradigma, los nuevos conocimientos convirtieron a los médicos en un grupo de elite que adquirió un prestigio que hasta entonces no había tenido y pasaron a tener un peso importante en la política nacional. Con ellos y bajo el paraguas del higienismo se produjo el auge de las actividades profesionales vinculadas a la higiene y la salud y a las necesarias reformas que debían aplicarse para adaptar las ciudades a las nuevas concepciones higiénico sanitarias. La medicalización de la sociedad y del Estado se produjo sobre el telón de fondo de una:

política de la salud que se distingue por: la necesidad de prevenir las enfermedades por la definición de la propia salud como algo observable en un conjunto de datos perfectamente medibles y cuantificables; por la determinación de variables características de grupos y colectividades en función de esos datos; el desarrollo de tipos de intervención que no son terapéuticos ni médicos en sentido estricto sino que se fijan en cuestiones como la vivienda, la manera de criar a los niños, la alimentación y los modos de vida y, por último por una integración por lo menos parcial de la práctica médica a una gestión económica y política, que apunta a racionalizar la sociedad. ${ }^{3}$

Poco a poco la sociedad y los poderes públicos se sometieron a los dictados de los científicos, pero este proceso no fue solo lento sino desigual. La «medicalización» se produjo a distintos ritmos en los diferentes países y, dentro de estos, hubo grandes diferencias entre lo rural y lo urbano y entre el centro y la periferia. No obstante, el proceso fue un fenómeno global que afectó de manera similar a las grandes ciudades en proceso de industrialización: «Where the industrial regions were an object lesson in vertically arrayed power, the great cities were an object lesson in contrast and motion. One must imagine nineteenth-century cities not as units but a congeries of neighborhoods, to walk through them was to pass trough a seemingly endless regress of social contradictions». ${ }^{4}$

Para atender a este fenómeno global se desarrollaron una serie de saberes que discurrieron a nivel internacional a partir de la circulación de los profesionales y de su participación en congresos internacionales y grandes exposiciones universales en donde se mostraban los resultados de las reformas llevadas a cabo, de manera más o menos exitosa, en las principales capitales europeas y americanas.

Como señala Folchi, no hay por el momento un estudio exhaustivo de la difusión del paradigma en Chile, pero sí varias evidencias de su

3 Foucault, 2012, 213.

4 Rodgers, 1998, 48. 
penetración a partir de la segunda mitad del siglo XIX a través de las figuras de médicos europeos que llegaron a ejercer la medicina o a impartir cátedra una vez que fueron creadas la carrera de Medicina — a instancias del británico Guillermo Blest - y, años después, la primera Facultad de Medicina, que quedó también bajo la dirección de un extranjero, el francés Lorenzo Sazié. ${ }^{5}$ La intelectualidad chilena comenzó a enviar a sus hijos a estudiar al extranjero con el fin de que adquirieran nuevos conocimientos en medicina, destacando, en este sentido, la iniciativa del médico José Joaquín Aguirre, quien en la década de los 70 impulsó las pasantías internacionales al extranjero para los jóvenes profesionales chilenos. ${ }^{6}$

Las medidas para hacer efectivas las nuevas teorías fueron, consecuentemente, mucho más lentas. En el primer número de la Revista Chilena de Hijiene, dirigida por Federico Puga Borne, se recopilan los antecedentes de la constitución del Consejo Superior de Higiene Pública, creado en 1889, y los debates habidos al respecto. En ese texto se denunciaba que la acción preventiva no existía y que las pocas medidas que se tomaban desde el gobierno en materia de higiene y salud eran, casi siempre, dictadas por la urgencia de situaciones concretas que terminaban quedando sin efecto cuando la emergencia desaparecía. ${ }^{7}$ Lo cierto es que hasta entonces las cuestiones de higiene y salubridad habían estado a cargo de los gobiernos municipales, los cuales carecían de recursos y de formación para emprender medidas de más largo alcance. El gobierno central tenía injerencia únicamente como órgano consultivo y normativo y eran las instancias particulares las que, frecuentemente, terminaban atendiendo las crecientes demandas en estas cuestiones. Como señala Durán, «el estado parlamentario no se encontraba preparado para acoger dichas demandas por lo que debieron ser los privados quienes asumieran el rol de asistentes». ${ }^{8}$ Coincidimos con él en que, si bien en la teoría tuvo el respaldo institucional, en la práctica la intelligentsia médica contó con escaso apoyo estatal. Se crearon instituciones desde las que se colaboraba en la difusión de las nuevas pautas, pero, como señalaba Puga Borne, fueron entes meramente pasivos; y así seguían siéndolo

5 Folchi, 2007, 373. Sazié fue, a su vez, el fundador de la escuela de matronas en 1834. La importancia de esta escuela en un país y en un momento en que las altas cifras de mortalidad infantil eran una de las principales denuncias de los higienistas y publicistas de la cuestión social, ha sido estudiada ampliamente por Soledad Zárate, 2007.

6 Zárate y Del Campo, 2014. Esos expertos galenos pasaron a dar un toque cosmopolita a la recién creada Sociedad Médica de Santiago, a la que se fueron sumando junto con los egresados de medicina de la Universidad de Chile.

7 Revista Chilena de Hijiene, 1, Santiago, 1894, 6.

8 Durán, 2009, 102. 
20 años después, como denunciaba también Pedro Lautaro Ferrer, quien las veía como entidades carentes de «facultades propias para determinar la acción pública sanitaria ni mucho menos para prevenir epidemias y organizar la defensa contra las enfermedades infecciosas». ${ }^{9}$

Por otra parte, y continuando con las opiniones de Ferrer, estas instituciones apenas si tenían presencia: «En muchos departamentos aún ni se han instalado y en la mayoría de los casos llevan una vida lánguida o inútil». ${ }^{10}$ Aun ni siquiera se les tenía en cuenta como asesores expertos en momentos críticos, como lo denuncia un periódico talquino en la década de 1880: «No formar una comisión semejante, querrá significar simplemente una de dos: o que la autoridad no se ocupa lo bastante de la salubridad pública, o que la autoridad entiende lo bastante de medicina para cuidar con acierto a los enfermos de viruela i para rechazar en hora oportuna la invasión». ${ }^{11}$

Cuando Lautaro Ferrer denunciaba, en 1911, la inutilidad de las instituciones, señalaba, esperanzado, que todo tendía a solucionarse puesto que se estaba discutiendo un nuevo código en el Congreso. No obstante, este código no fue aprobado hasta 1918 y todavía tuvo que ser reformado en 1925 para hacerse realmente efectivo. ${ }^{12}$ Por otra parte, los antecedentes de estos códigos, según el propio Ferrer, se remontaban a «la Ley de Policía Sanitaria del año 1886 y a la Ordenanza General de Salubridad de 1887, organizaciones anticuadas que no corresponden a los conocimientos modernos de la medicina y de la higiene y que están en pugna con los Pactos sanitarios internacionales que son leyes de la República». ${ }^{13}$ Con estas palabras, Ferrer se condolía de que todavía en 1911 estuvieran vigentes leyes que establecían la obligación del cierre de puertos y declaración de cuarentenas, a pesar — decía - de que los descubrimientos de la bacteriología habían demostrado que dichas medidas eran totalmente ineficaces para acabar con la enfermedad. Los nuevos conocimientos no habían servido para cambiar una sola coma en leyes aun vigentes y, mucho menos, en las prácticas.

Aquellos acuerdos internacionales a los que hacía referencia el especialista, eran los que se adoptaron a partir del Pacto de Washington de 1905, fruto de las discusiones habidas en la serie de conferencias panamericanas

\footnotetext{
9 Ferrer, 1911, 36.

10 Ibidem, 38. Los departamentos eran las unidades político-administrativas en las que se organizaban las provincias.

11 La Libertad, 5 de febrero de 1880.

12 Hevía, 2006, 171. Ley n ${ }^{\circ}$ 3385. Código Sanitario, Imprenta Central, Santiago, 1918; Código Sanitario de la República de Chile, Diario Oficial, 20 de octubre de 1925.

13 Ferrer, 1911, VIII.
} 
y europeas que venían celebrándose desde la centuria anterior. ${ }^{14}$ En estas reuniones se había discutido con amplitud todo lo relacionado con la salubridad urbana, sobre todo la de los puertos, tenidos como puntos de enlace y, por tanto, como posibles focos de infección y contagio permanente. Las disposiciones ahí tomadas tenían gran relevancia en los países participantes, como señalaba Ferrer cuando equiparaba los «pactos sanitarios internacionales» con las «leyes de la República».

La primera de estas conferencias panamericanas, la de 1902, celebrada también en Washington, estableció una Oficina Sanitaria que tenía, entre otras, las siguientes funciones:

pedir a cada República que remita pronta y regularmente a dicha Oficina todos los datos de toda clase relativos al estado sanitario de sus respectivos puertos y territorios. [...] Pedir a cada República que proporcione a dicha Oficina todo el auxilio posible para que haga un estudio detenido y científico de las invasiones de cualquiera enfermedad contagiosa [...] prestar el mejor auxilio que pueda y toda la experiencia que posea para contribuir a que se obtenga la mayor protección posible de la salud pública de cada una de dichas Repúblicas, a fin de que se eliminen las enfermedades y de que se facilite el comercio entre las expresadas Repúblicas. ${ }^{15}$

Se percibe en el texto una clara intención de proteger las zonas de contacto internacional y una confianza ciega en que el control científico-técnico. La difusión y control internacionales redundarían en el desarrollo de las relaciones comerciales y de la paz social:

Un indicio importante de ese proceso fue el papel significativo que en la exposición universal de Paris de 1900 adquirió el pabellón dedicado a la «economía social». Si bien el mensaje que quería trasmitir la exposición era de plena confianza en los logros del capitalismo industrial y el auge del comercio, no podía ocultarse la ansiedad que para la «paz social» producían los crecientes conflictos entre los trabajadores y el capital, fenómeno bastante globalizado que afectaba a todas las grandes orbes del mundo. Bajo el paraguas de la «economía social», concepción impulsada por el teórico francés Charles Gide, el pabellón incluía todo tipo de iniciativas de reformas que iban desde las más estatistas, de origen alemán, hasta las más asociativas y cooperativas, como las francesas y belgas. ${ }^{16}$

14 González Leandri, 2013b. Los primeros congresos internacionales de Higiene tuvieron lugar en en Bélgica en 1851, 1852 y 1875; París, 1878; Turín, 1880; Génova, 1882; La Haya, 1884; Viena, 1887 y París, 1889.

15 Oficina Sanitaria Panamericana, «Las Conferencias Sanitarias Internacionales de las Repúblicas Americanas y la Oficina Sanitaria Panamericana», Boletín de la Oficina Sanitaria Panamericana, [1927], 586, http://iris.paho.org/xmlui/bitstream/handle/123456789/13912/v6n8p586. pdf?sequence=1\&isAllowed=y [Consultado: 26/01/2015]. Las cursivas son nuestras.

16 González Leandri, 2013a, 41. 
Para aterrizar el discurso en la sociedad se diseñaron una serie de mecanismos destinados a introducirlo en las escuelas a través del adoctrinamiento de los docentes. Para ello, junto a estas grandes reuniones internacionales, se organizaron congresos higiénico- pedagógicos en los que se fijaban los principios organizacionales para la introducción de la higiene en el currículo escolar. ${ }^{17}$

\section{La educación como vía de penetración del paradigma}

Con un acuerdo tácito sobre lo que había que hacer y ante la falta de recursos y de facultades punitivas de las autoridades para llevar a cabo un plan eficaz de reforma y de control, se pusieron grandes esperanzas en la divulgación, bajo la premisa de que el adoctrinamiento de la población incidiría en mejores prácticas. Así lo señalaba, desde la perspectiva del catolicismo y de la economía social, uno de los principales impulsores del reformismo en Chile, Juan Enrique Concha Subercaseux, en una conferencia pronunciada en la Universidad Católica de Santiago: «Yo no soy de los que creen que las cuestiones sociales se resuelven únicamente por medio de las leyes, como por obra de encantamiento; y por lo contrario, mucho más que en la influencia de las leyes creo en la acción educativa que ejercen las diversas clases sociales con el cumplimiento de sus deberes peculiares y con el respeto recíproco de sus derechos». ${ }^{18}$

Desde sus posiciones políticas los reformistas, católicos o no, impulsaron iniciativas tendentes a introducir el paradigma a través de la educación. Este proceso de adoctrinamiento se realizó de forma paralela al proceso institucionalizador; de hecho fue uno de los recursos más amplios con los que contaron las instituciones para aumentar su efectividad. No bastaba con detectar la situación sino que se hacía necesario que fuera percibida como problemática por la sociedad, para que hiciera suyo el discurso y lo adoptara, para poner en marcha las prácticas que acabarían con el problema. Como señala Lezama: «La función regulatoria de las instituciones depende de la construcción discursiva de los problemas. No es la crisis física del medio ambiente lo que provoca el cambio social, tampoco la destrucción de ciertos bienes socialmente valorados, sino la creación de imágenes, problemas

17 Martínez Moctezuma, 2006. En México, por ejemplo, se celebraron en un lapso de diez años, tres congresos de esta índole en 1882,1889 y 1891.

18 Concha, 1918, 202. 
identificables que permiten a la gente con posiciones y perspectivas diferentes, compartir una imagen común de lo que puede ser considerado un problema». ${ }^{19}$

En 1872 se incluyó la higiene como materia obligatoria en las escuelas fiscales y, poco después, se hizo la formación con los propios maestros: «en 1890 el Programa de estudios de la Escuela Normal de Preceptores de Santiago incluyó el curso de Higiene, que constaba de una hora semanal, y el reglamento de 1898 estableció su enseñanza en las escuelas superiores y elementales dentro de las Ciencias físicas o naturales. En 1909, las escuelas normales de mujeres tuvieron en el último año de estudios una clase destinada al Cuidado Higiénico y Alimentación de Niños hasta la edad de 5 años». ${ }^{20}$ Como señala Terrón para el caso español:

colocar bajo la autoridad de los poderes públicos (estado o autoridades locales) y sus expertos (médicos y maestros, también psicólogos, paidólogos...) un segmento universal de población (la comprendida en la edad escolar obligatoria), se facilitaba, frente a las resistencias que en otros espacios podían presentar los sectores populares [...] la inculcación de unos determinados hábitos de vida en relación con el vestido, el sueño, la alimentación, los ritmos de trabajo y reposo, etc., irán conformando los deseos y las necesidades de quienes se quiere sean ciudadanos sanos, saludables y productivos. ${ }^{21}$

Lo mismo ocurría en Chile, donde Ximena Urbina nos habla de una infancia «colonizada» - y con ella sus padres - a través de la educación escolar en higiene. ${ }^{22}$ Esa «colonización» se fue produciendo de manera lenta y paulatina, y para la tercera década del siglo XX ya sí se puede hablar de algo más que de un éxito relativo, al menos en al ámbito urbano.

No obstante, hasta entonces el incumplimiento de la normativa era frecuente si atendemos a que todavía en 1925 uno de los principios del Código Sanitario señalaba que en las escuelas no podrían aceptarse alumnos sin cartilla de vacunación puesta al día. Llama la atención esta disposición teniendo en cuenta que la vacunación era obligatoria desde 1918 y que los primeros pasos en pos de la erradicación de la viruela se habían dado mucho tiempo atrás, en 1808, con la creación de la Junta Central de Vacuna. Sin duda, esta disposición incluida en el Código Sanitario de 1925 viene a

19 Lezama, 2004, 50.

20 Rengifo, 2012, 160-161.

21 Terrón, 2000, 75.

22 Urbina, 2011. 
poner en evidencia, como veremos más adelante, las resistencias al cumplimiento de las leyes sanitarias.

Los directores de las escuelas hacían la «vista gorda» ante la falta de la cartilla en regla, pero también en cuanto al cumplimiento de medidas higiénicas dentro de la escuela. Los esfuerzos programáticos destinados a imponer normativas higiénicas en los colegios eran resistidos de muchas formas, como evidencia, por ejemplo, la práctica habitual de hacer llegar tarde a los niños para evitar la revisión diaria y la consecuente amonestación pública, lo cual afectaba además al buen funcionamiento de la jornada escolar. ${ }^{23}$

Todo ello ocurría porque a las escuelas se les exigían normas higiénicas difíciles de cumplir con los recursos y la realidad en que se encontraban insertas. Así lo señalaba la doctora Eloísa Díaz, inspectora médica escolar, en la sección de higiene del Congreso Médico Latinoamericano de 1902, quien denunciaba que era imposible que se exigiera a las escuelas que contaran con agua potable y alcantarillado cuando estos servicios no existían más que en algunas zonas de las principales ciudades. ${ }^{24}$

Otras vías de difusión fueron las revistas especializadas y los congresos médicos, que contaban, con frecuencia, con secciones dedicadas a la higiene y también a la pedagogía. La Revista Chilena de Hijiene, la Revista Médica de Chile y el Boletín del Consejo de Hijiene Pública son muestra del interés despertado por la salud y la higiene durante la transición del siglo XIX al XX. Anteriormente circuló la Revista Médica de Santiago, fundada en 1856 por el homeópata Benito García Fernández y de la que fueron suscriptores personajes tan influyentes como Francisco Ruiz Tagle, Manuel Montt o Victorino Lastarria.

Destacan también, entre las labores de difusión, las «cruzadas médicas» lideradas a inicios de 1920 por Ferrer, quien, nombrado por el Comité Central de la Cruz Roja, Director General de las Cruzadas de Salud Pública, recorrió el país equipado con un tren sanitario y acompañado de personal médico, estudiantes de medicina y enfermeras voluntarias de la Cruz Roja de las Mujeres de Chile, adoctrinando sobre salubridad y prevención de epidemias y enfermedades venéreas, fortalecimiento de la infancia, etc.

La insistencia en la difusión venía siempre acompañada por la tiranía de las cifras reflejadas en las estadísticas que comenzaron a proliferar en la segunda mitad del XIX. Continuamente los comentarios a estas estadísticas venían acompañados de comparaciones con las cifras presentadas en

23 Serrano, Ponce de León y Rengifo, 2012, 222.

24 Ibidem, 146. 
otras capitales en las que — se decía — la aplicación del higienismo se venía practicando desde tiempo atrás y de manera más efectiva. De esta forma, unas buenas cifras eran la mejor carta de presentación para poder mantener relaciones comerciales competitivas en el mercado internacional. Todo ello acompañado de una fe ciega por parte de los especialistas en que «la cuantificación de los seres humanos daba la posibilidad de un cambio cualitativo en la percepción de las sociedades y sus miembros». ${ }^{25}$

Así, la higiene se presentaba abiertamente como una condición para el desarrollo económico y cultural del país. Se pretendía como una suerte de fórmula para obtener la mejora del organismo social, y también la de los individuos, y con ello incluso se llegaba a hablar del «perfeccionamiento de la raza». Algunos de estos argumentos se discutirán en Raza Chilena ${ }^{26}$ y en Nuestra Inferioridad Económica, ${ }^{27}$ donde Francisco Antonio Encina destacaba rasgos de los chilenos como la falta de perseverancia, la debilidad del espíritu de asociación y cooperación, el derroche del tiempo, etc., entre los factores responsables de la supuesta situación de inferioridad del país. ${ }^{28}$

El nuevo paradigma se constituyó, así, en el vehículo para mejorar la especie, como refleja el higienista Ricardo Dávila Boza en su programa de higiene escolar:

No se nos tache de difusos si damos a esta parte alguna mayor extensión de la que le correspondería en un tratado especial de hijiene privada i personal porque no partiendo nosotros del principio de que la HIJIENE no tiene por objeto la sola conservación de la salud, sino también el perfeccionamiento del organismo en cuanto cabe en el campo fisiológico, es natural que no nos limitemos a indicar las precauciones que deben tomarse para evitar que los alumnos contraigan alguna enfermedad, sino que nos extendemos también en considerar los medios de que podemos valernos para dar a su organismo el mayor grado de perfección de que sea posible. ${ }^{29}$

De entre las cifras más alarmantes que se repetían constantemente, destacaban siempre las de la mortalidad. Adolfo Murillo señalaba que el número de defunciones en la ciudad de Santiago apenas había bajado del 45 por mil en 1895 y que esa sería una cifra para celebrar, dados los altos índices de años anteriores, si no fuera porque en otras capitales la diferencia

25 Mayer, 2014, 86.

26 Palacios, 1918 [1904].

27 Encina, 1955 [1911].

28 Godoy, 1982, 447. Sobre la relación entre ciencia, racismo, higiene y eugenesia en Chile y en América Latina ver Leyton, Palacios y Sánchez, 2015.

29 Dávila, 1884, 85. 
era abismal. Daba como ejemplo, para 1894, año en que la mortalidad fue en Santiago del 46,14 por mil, las cifras para Montevideo, donde había sido del 16,0; para Buenos Aires, del 20,1; para Río de Janeiro, 29,6; para Nueva York, del 21,4; Filadelfia, 20,0; Nueva Orleans, 27,6 y Chicago tan solo del 13,9 por mil. Y denunciaba a continuación que era aun peor la infantil, que no había bajado durante años del 58 por mil. ${ }^{30}$ La responsable de estas cifras era nuevamente, a su juicio, la falta de educación:

\begin{abstract}
No es, pues, escasa la mortalidad infantil de la ciudad de Santiago y precisa ponerle remedio. Porque remedios existen para disminuirla y a ello nos obligan deberes ineludibles. No creo que basten el alcantarillado ni el abastecimiento abundante y barato de una buena agua potable. Hay que instruir a1 pueblo, educarlo; levantar su espíritu y hacerle comprender el bien de una vida sana y la influencia fatal de los vicios en la morbilidad y en la muerte prematura. Pero para eso precisa el ejemplo que evangeliza; la escuela que reforma la habitación, que hace gente sana, que proporciona medios de trabajo y asilos que restauren las fuerzas perdidas y que curan las dolencias del cuerpo y aún las del alma. La miseria del pueblo es mayor de la que se cree: se impone el socorro de las madres desvalidas, la suministración de leche esterilizada para la crianza de los niños. ${ }^{31}$
\end{abstract}

En esta misma línea se expresaba otro médico, Augusto Orrego Luco, quien publicó una serie de artículos en la prensa de Valparaíso en torno a la «cuestión social» en Chile. En su crítica a la miseria del pueblo llegó a plantear la defunción infantil como una vía de escape para los problemas sociales: «En medio de la miseria, la higiene es imposible, y la falta de higiene es mortal para el recién nacido [...] En el bajo pueblo la muerte del hijo es una fiesta». ${ }^{32}$

Como respuesta a esta continua crítica que relacionaba la miseria física con la moral y que depositaba en la clase trabajadora la responsabilidad en el incumplimiento de las nuevas disposiciones, la prensa obrera y algunas organizaciones de trabajadores comenzaron a hacerse eco y a convertirse en portavoces del paradigma, lo que pone en evidencia la asunción del mismo. De entre la prensa obrera destaca El obrero ilustrado, revista quincenal dirigida por Guillermo González, que inicia su tirada en la emblemática fecha del primero de mayo de 1906, como la primera publicación periódica en Chile en tener un departamento y un redactor especiales para hablar de higiene.

30 Murillo, 1896, 8-11.

31 Ibidem, 15.

32 Orrego Luco, s.f. [1884], 33. Sus opiniones fueron vertidas en La Patria de Valparaíso en 1884 y recogidas en un volumen titulado La cuestión social. 
Años después se constituyó desde la IWW un periódico dedicado en exclusiva a la difusión del higienismo entre los trabajadores: la Hoja Sanitaria. En su presentación se pone de manera dogmática el discurso en un tono totalizador al señalar que darían «una batalla sin cuartel a lo que comenzó a conocerse como automedicación y también a los denominados "charlatanes", que según el discurso que comenzaba a imperar lucraban con los problemas de salud de los obreros, generando graves complicaciones de las enfermedades que éstos padecían». ${ }^{33}$

La Hoja Sanitaria era emitida desde el policlínico que la propia IWW había creado para la atención de los trabajadores y se encargaba de difundir nociones básicas de anatomía y consejos para la prevención de enfermedades, evidenciando la importancia que adquirió en las primeras décadas del siglo XX la cuestión de la salud y la prevención en la lucha obrera. Se asumió y reprodujo el paradigma; también la reverencia a lo «científico» y a la profesión médica caló en el discurso de los trabajadores, como evidencia, por ejemplo esta cita aparecida en la Hoja Sanitaria en la que se destacaba la labor del médico Walter Fernández, de quien se decía que: «La forma más sublime del heroísmo es la proporcionada por el héroe científico; la del hombre que, conociendo los peligros de una enfermedad, se la produce inoculándose los parásitos que la determinan a objeto de beneficiar a sus semejantes». ${ }^{34}$

Tampoco los editores de la Hoja Sanitaria estuvieron ajenos a inmiscuirse en la cuestión moral y en la clasificación y reglamentación de las conductas. Si los higienistas establecían pautas hasta para señalar cómo debían reír los niños, sentarse o escuchar, ${ }^{35}$ a los de la IWW no les temblaba el pulso a la hora de tratar cuestiones como, por ejemplo, la definición del «verdadero amor» que no era otra cosa que «atracción material del sexo masculino por el femenino, iluminado y mantenido por la comunión intelectual y moral del hombre y la mujer que se aman». ${ }^{36}$

En esa misma línea, mantenían que las «malas prácticas» y la «degradación moral» eran las responsables de la mayoría de las enfermedades y pandemias. Así lo recogían otros periódicos como La Gran Federación Obrera de Chile, en donde se reproducían las palabras de Eduardo Wolleter a través de las cuales se prevenía a los trabajadores para disuadirlos de asistir a los hospitales, al tiempo que, con un sesgo marcadamente segregacionista,

33 Citado por Pávez, 2009, 426.

34 Ibidem, 428.

35 Dávila, 1884.

36 Citado por Fuster y Moscoso-Flores, 2012, 194. 
señalaba que los hospitales públicos eran buenos para el cuidado de los obreros inmigrantes, pero no para los que vivían en familia, puesto que muchos de los enfermos lo estaban a causa de sus malas conductas:

Pero los establecidos, los que viven en el seno de su familia, esos no deben ir jamás al hospital, deben hacer de modo, con su previsión y sus economías, que no lo necesiten nunca. Verdad es que en los hospitales hay cuidados continuos e inteligentes. Medicamentos apropiados, servicio regular y lo mejor gratis: todo unido a la bondad de los médicos y a la inagotable paciencia de las hermanas de la caridad. El obrero debe procurar dejar este recurso a los abandonados de su familia; los compañeros no deben olvidar que si el recurso del desgraciado es el hospital, es también en muchos casos el castigo de una mala conducta pasada. ${ }^{37}$

También hubo organizaciones y médicos consagrados a la difusión del paradigma entre los mutualistas, que contaron con el apoyo de médicos como Francisco Galleguillos Lorca, que dio conferencias en las sedes de la Unión de Carpinteros, en la Filarmónica de Obreros y en la Agrupación Demócrata, además de colaborar en periódicos como La Voz de la Democracia y La Opinión del Pueblo. ${ }^{38}$

La difusión se percibe también fuera de Santiago, en provincias como Iquique, con periódicos como Renovación, publicado por la imprenta de los Talleres de la Unión Popular, o Defensa Obrera, que en 1917 instruía a la población de Calama sobre cuestiones sociales en general y las condiciones higiénicas de Chuquicamata en particular; también en Antofagasta, con El Guerrillero Local, editado por Oscar A. Chanks, presidente de la agrupación Antofagasta del Partido Demócrata, que se preocupaba semanalmente de informar y asesorar a sus lectores sobre higiene y previsión, etc.

Esta proliferación de periódicos y de organizaciones preocupadas por hacer llegar los postulados del higienismo a la sociedad, habla por sí misma del interés creciente de las organizaciones obreras por la asunción y la implementación de las normas, lo cual nos lleva a buscar las resistencias al cambio en otros ámbitos distintos.

\section{Resistencias a la aplicación de las leyes}

A través de las campañas de divulgación ese discurso homogeneizador y totalizador fue calando en una ciudadanía que habitaba en poblaciones en constante crecimiento, a las que cada día llegaba la inmigración procedente

37 La Gran Federación Obrera de Chile, Santiago, 10 de diciembre de 1910, 3.

38 López, 1912, 170. 
de otros países o del entorno rural. En este contexto, las ciudades crecieron de manera desigual. No tenían nada que ver las infraestructuras del centro urbano comercial y de los negocios con las de la periferia, y esto ocurría tanto en Santiago y en el puerto de Valparaíso como en las pujantes capitales de provincia como Talca. ${ }^{39}$ La desigualdad de condiciones de inversión y de atención entre el centro y la periferia tuvo importantes consecuencias sanitarias que incidieron en el desarrollo de epidemias y en el, igualmente desigual, reparto de los efectos fatales entre la población perteneciente a uno u otro sector. Residir en uno u otro barrio podía suponer la barrera entre la vida y la muerte, en muchas ocasiones. Así lo expresaban los médicos Salamanca y Molina, en la memoria presentada para solicitar que la empresa de agua potable pasara de la municipalidad al gobierno central:

la I. Municipalidad lleva invertida en mejoras de tan importante servicio, la no despreciable suma de \$95.521 suma que ha sido de sobra compensada no solo por el subido interés que ese dinero produce a la Corporación sino por las inmensas ventajas de comodidad i bienestar prestados al vecindario, y mui especialmente por el notorio mejoramiento del estado sanitario de la población. A medida que se estienden los servicios de agua potable, se ve disminuir progresivamente las disenterías i fiebres tifoideas tan frecuentes y mortíferas en épocas anteriores. ${ }^{40}$

Señalaban también, al final del escrito, que la cuestión de la salud era pública y que debía, por tanto, ser responsabilidad nacional y no local o privada, no solo por una cuestión social sino por la dificultad de establecer cordones sanitarios verdaderamente efectivos si se hacía solo de manera localizada: «los problemas de administración local cuya solución reclaman la salubridad i la hijiene, no atañen solo a un pueblo determinado. Ellos benefician o amenazan a la comunidad en jeneral i son por lo tanto incumbencia propia i legitima del gobierno central de la Nación». ${ }^{41}$

Si bien en la década de 1870 se había aceptado como suficiente el establecimiento de los caminos de cintura y la separación de barrios marginales como los planteados por Vicuña Mackenna en Santiago o por Echaurren en Valparaíso, en vísperas del centenario para los reformistas ya no era aceptable considerar la higiene y la salud en la ciudad de manera segmentada. Las reformas debían afectar a toda la ciudad y a todos los sectores sociales para ser realmente efectivas.

39 Simón, 2013. Sánchez y Simón, 2015.

40 Molina y Salamanca, 1894 [sin paginación].

41 Idem. 
Inevitablemente, los sectores marginados por las primeras reformas fueron tomando conciencia de la desigualdad y de lo que ella generaba una vez que se apropiaron del discurso; sus voceros, con sus denuncias, se constituyeron en un elemento más de difusión del mismo, aportando su propia visión de cómo debían implementarse las reformas, convirtiéndose así en promotores de políticas públicas y no en meros receptores pasivos, o incluso en rémoras para su implementación, como recurrentemente denunciaban los publicistas de la cuestión social. La preocupación por la «otra mitad $»^{42}$ no debía limitarse a describir cómo vivía la población, sino a entender cómo quería vivir una vez que se apropió del discurso. Para algunos publicistas no era que la degradación y la falta de cultura llevaran a la población a oponerse a las reformas, sino que sus condiciones económicas les impedían hacerlo de otra manera. Y esto que parecía ya una evidencia a principios del siglo XX, no lo había sido tanto durante la segunda mitad del XIX. En un editorial de El Ferrocarril de 1872 se explicaba, casi con asombro, cómo estos trabajadores tenían otras aspiraciones que, cuando no se veían cumplidas, emigraban en busca de condiciones más óptimas para vivir: «Ya es tiempo que nos ocupemos seriamente del bienestar de nuestras clases trabajadoras. La corriente de emigración que se produce en sus filas cada vez que asoma en el extranjero una expectativa cualquiera de fortuna, si puede atribuirse en algo al espíritu de aventuras, prueba al mismo tiempo que esas clases sienten aspiraciones a una condición mejor». ${ }^{43}$

La cuestión social en Chile ha sido contemplada como un proceso iniciado a partir de las transformaciones generadas por la revolución industrial ${ }^{44}$ o por el flujo de inmigrantes del campo a la ciudad; $;{ }^{45}$ otros autores han llegado a considerar que no fue un fenómeno propio del XIX sino que es posible hablar de una cuestión social colonial y otra contemporánea; ${ }^{46}$ mientras que Garcés realiza una distinción entre los elementos objetivos y subjetivos que la alimentaron en Chile. Estos elementos subjetivos, según señala Reyes, parafraseando a Garcés, ${ }^{47}$ serían aquellos que conformaron las respuestas de los diferentes grupos sociales a los cambios surgidos durante el proceso de cambio en las ciudades a finales del siglo XIX y principios del XX. Consideramos que, en definitiva, estos elementos subjetivos fueron

42 Riis, 2004 [1888].

43 Reproducido en Grez, 1997, 211.

44 Morris, 2000.

45 Vial, 1981.

46 Grez, 1997.

47 Reyes, 2010. 
fundamentales pero que no solo deben centrarse en cómo enfrentaron los problemas sino cómo los percibieron y cómo los construyeron. En este sentido, consideramos que las cuestiones relacionadas con la higiene y la salud no fueron percibidas como problema por parte de las clases trabajadoras hasta que el discurso higienista no fue asimilado por completo. Es más, durante una primera fase en la que ya se consideraba como tal, no se contempló que fuera una responsabilidad del Estado o, dicho de otro modo, se consideró que, dada su importancia, no debía dejarse en manos del gobierno. Con gran acierto, Molina Bustos se lamenta de que con frecuencia la historiografía que hace referencia a la evolución de las instituciones de salud en Chile, la presenta como algo lineal que parte de lo privado a lo público y que va de lo particular a lo general como una cuestión inevitable. Esta visión teleológica del progreso institucional no es acertada, sino que fue fruto de intensos debates y de un permanente ejercicio de cuestionamiento que se dio en todos los ámbitos. ${ }^{48}$ Hubo una serie de resistencias a dejar la salud y la higiene en manos del Estado; ahora bien, dichas resistencias no vinieron de los sectores más perjudicados por la exclusión del nuevo modelo sino de ciertos grupos, que se oponían a ampliar el aparato del Estado y a promover la intervención del mismo en aras del «laissez faire».

A pesar de que las primeras juntas de vacuna contra la viruela se habían organizado en Chile durante las primeras décadas del siglo XIX, todavía en la década de 1920 las cartillas de vacunación seguían sin estar al día. Resulta llamativo que tras un siglo de «persecución» contra la enfermedad, todavía la viruela siguiera cobrándose centenares de vidas cada vez que se producía una epidemia. Para explicar la persistencia de las epidemias, en esta cuestión, como en otras ya señaladas relacionadas con la higiene y la salud, se insistía nuevamente en que era el pueblo el que se resistía a ser vacunado. No obstante, no tenemos constancia de que en Chile se produjera un fenómeno similar al de la Revolta da Vacina ocurrida en Río de Janeiro en 1904, que vino dada por parte de los sectores populares que se negaron a ser vacunados como respuesta a una serie de medidas que habían sido tomadas a iniciativa de higienistas como Carlos Chagas y Saturnino de Brito, en aras de la higienización y la modernización del país. ${ }^{49}$

En Chile la cosa fue diferente y si bien hubo oposición, esta no vino dada precisamente desde los sectores populares. La Junta Central de Vacuna consideraba que para que la vacunación se hiciera efectiva era necesario

48 Molina Bustos, 2010, 8.

49 Rodrigues Soares, 2000. 
que se impusiera como una cuestión obligatoria. Tras muchas insistencias, dicha iniciativa fue llevada al Congreso por Balmaceda en 1886, donde encontró oposición férrea por parte de los diputados opositores al intervencionismo del Estado en lo que ellos consideraban cuestiones de la vida privada. Ante esto, Adolfo Murillo, médico y diputado por Santiago, apelaba a la situación de otros países considerados garantes de las libertades, que habían acogido la obligatoriedad de la vacuna así como la prohibición del trabajo infantil y un largo etcétera de medidas de este calibre, bajo la idea del bien común y del progreso de las naciones, y terminaba su emotivo discurso diciendo que «el prudente despotismo de la lanceta» era la única y verdadera salvación del país. ${ }^{50}$

A estos planteamientos, la Gran Convención Conservadora contra argumentaba: «la escuela que nos gobierna i que se da pomposamente a sí misma el título de escuela liberal, es precisamente la que no ha dejado libertad que no haya amagado o combatido, desde la libertad de la conciencia hasta la libertad de la vacunación [...] ¿Sabéis lo que ese liberalismo cesáreo nos ofrece en cambio? Enseñanza obligatoria o forzada, vacunación obligatoria o forzada, hasta cementerio laico obligatorio o forzado». ${ }^{51}$

Las resistencias a la educación y la vacuna obligatorias o a los cementerios civiles fueron agrupadas por Dávila Boza bajo la denominación de «resistencias pasivas».52 Y si bien no constituían confrontaciones violentas al cumplimiento de la legislación o a la implementación de las reformas, constituyeron un obstáculo constante a la aprobación de las leyes debido a la situación de poder que ejercían sus representantes en el Congreso. Estas «resistencias pasivas» se daban, precisamente, no por resistencia popular, sino por las oposición que propietarios agrícolas e industriales ponían al cumplimiento de las nuevas normativas en materia de higiene y salud.

Los congresistas que abominaban del liberalismo cesáreo representaban el sentir de los propietarios de las viviendas y los empresarios que se veían afectados económicamente con la implementación de las nuevas normativas. Poco a poco los reformistas fueron asumiendo que era necesario hacer grandes inversiones para la higienización de las ciudades y que, dadas las resistencias existentes, era necesaria la intervención del Estado. Si se

50 Murillo, 1883.

51 La Gran Convención Conservadora de 1878. Manifiestos, discursos, conclusiones, Santiago de Chile, Imprenta de «El independiente», 1881, 33-34, https://www.bcn.cl/Books/La_gran_ convencion_conservadora/index.html\#p=1 [Consultado: 10/04/2016].

52 Citado por Cabrera, 2008. 
quería erradicar las supuestas malas costumbres de los sectores populares había que invertir algo más que palabras y normativas. Así se señalaba, por ejemplo, en el citado editorial de El Ferrocarril de 1872, desde el que se instaba al gobierno a que estimulara la reconstrucción y edificación de habitaciones obreras para que los trabajadores, cómodamente instalados, tuvieran razones para «radicarse al hogar y a la patria» y abandonaran así la idea de emigrar y la costumbre de acudir diariamente a las tabernas; y para convencer a aquellos que más se resistían a la intervención, señalaba que nada de ello iría en menoscabo de los potenciales accionistas:

Queremos habitaciones que fueran el conventillo mejorado, pues serían el conventillo salubre, con jardín, con agua potable, con interiores bien arreglados, hasta con gas, porque allí podría llegarse sin inconveniente. A lo menos nada sería más fácil que hacer un ensayo. Santiago, que ha dado tantos puñados de escudos para edificar hospitales, ¿por qué no prestaría los fondos necesarios para ensayar la construcción de habitaciones de obreros? Si el ensayo era desgraciado, la pérdida sería escasa, pues los accionistas tendrían la propiedad del terreno y de las construcciones. Si el ensayo andaba con fortuna iqué progreso $!^{53}$

Así lo señalaba también Arturo Alessandri en 1893, cuando proponía que el Estado apoyara con subvenciones a los constructores y a los propietarios de viviendas para que las adaptaran a las nuevas exigencias de salubridad y también que procediera con multas y represión contra aquellos que las contravinieran, llegando incluso a la demolición en los casos de incumplimiento flagrante:

el único medio eficaz para librar a nuestras poblaciones de los profundos males con que las amenaza el mal estado de las habitaciones del pobre, está en el desarrollo y perfeccionamiento del recién fundado Consejo de Higiene, en la difusión de la instrucción pública y en una ley que confiera todo género de facultades en esta materia al Consejo de Higiene, donde sea posible su acción, y a las autoridades administrativas donde esta no alcance, facultades que deben mirar tanto a la construcción de las habitaciones como a la inspección de los hábitos higiénicos de sus moradores. ${ }^{54}$

La solución propuesta por Alessandri y los defensores de la cuestión social era, en definitiva, técnica, no política. No se trataba de acabar con las desigualdades, sino de procurar que aquellos que trabajaban de sol a sol

53 Reproducido en Grez, 1997, 213.

54 Ibidem, 395. Marcaba, eso sí, más adelante que no era aconsejable que el Estado se convirtiera en promotor pero que sí debía presionar a los propietarios o subvencionarlos de alguna manera. Lo que en esos momento no podía plantearse, la intervención directa del Estado, fue sin embargo lo que 27 años después llevó al propio Alessandri a la presidencia de la República. 
tuvieran un sitio más o menos salubre para volver y evitar así la emigración, la violencia y el contagio. El problema se percibía como económico, no como una cuestión de justicia social.

Más abiertamente intervencionista fue el nacionalista Nicolás Palacios, quien exigía la persecución de los que él consideraba los verdaderos responsables de la lentitud en la aplicación de las reformas. Los infractores, señalaba, eran los dueños de los conventillos, aquellos que, lamentablemente, eran los únicos que podrían imponer por ley las reformas, como miembros influyentes que eran de la política nacional:

Es común oír a los santiaguinos que por algún acaso visitan los barrios de obreros y artesanos de la capital, exclamar indignados: ¡mire Ud. cómo viven esos rotos miserables! ¡Cómo no han de morir como moscas habitando chozas inmundas, conventillos pestilentes, verdaderas pocilgas! El roto no tiene hábito el que menor de higiene! En un solo cuarto una familia entera! Chozas inmundas y conventillos pestilentes es lo único que allí encuentran para arrendar el jornalero de Santiago y el de los campos que llegan a la capital en busca de trabajo. Ricos, gobernantes, son generalmente los que han hecho construir esas chozas y esos conventillos. ¿Podrán alguna vez cambiar en habitaciones humanas esas pocilgas? Creo que no. El peón ni el operario a jornal de los talleres ganan lo suficiente para pagar un arriendo que equivalga al interés corriente del capital que sería necesario invertir en viviendas propias de hombres civilizados. Podrían los dueños de tales chozas dictar una ley para que el Fisco les garantizara un buen interés del capital que invirtieran en casitas para obreros, o acordara primas u otro expediente cualquiera que hiciera cesar el espectáculo vergonzoso que presentan los arrabales de la capital. Esperar que esos acaudalados santiaguinos sacrifiquen su bolsillo en provecho de un pueblo que miran con desdén y que creen de raza inferior, es esperar en vano. Para eso se necesita que vengan otros tiempos. ${ }^{55}$

En esa misma línea, la Revista de la Habitación señalaba que en Valparaíso la supuesta resistencia obrera a abandonar los conventillos y a oponerse a su destrucción, no era más que un engaño, pues los verdaderos interesados en evitar las demoliciones eran los propietarios de los inmuebles:

La primera dificultad que encontrará US. para proceder enérgicamente contra los propietarios de habitaciones obreras antihigiénicas, será el clamor de voces interesadas en hacer creer que es un atentado contra los intereses de los obreros el hacer demoler actualmente las habitaciones de carácter inhabitable y el desalojar aquellas que deben ser reparadas. Esas voces no son de los obreros que se dicen perjudicados, sino de los mismos propietarios que no quieren gastar en mejoras de las habitaciones que arriendan. ${ }^{56}$

55 Palacios, 1918 [1904], 48.

56 «Nota de Alberto Mackenna S. al intendente de Valparaíso con motivo del comienzo de su administración», Revista de la Habitación, 4, Santiago, 1921, 277-278. 
Para compensar la resistencia de inversionistas y propietarios de viviendas populares, así como la escasa intervención estatal en la puesta en práctica de la normativa, se diseñaron estrategias similares a la autogestión del policlínico de la IWW en materia de vivienda. Destacan en este sentido, en ciudades como Santiago y Valparaíso, las acciones de autoconstrucción de viviendas obreras por propia iniciativa y con apoyo en ocasiones de la Iglesia católica o de sociedades filantrópicas, ${ }^{57}$ que suplieron en parte, sobre todo en la capital, el incumplimiento de la aplicación de la Ley de Habitaciones Obreras de 1906.

Ni la participación masiva en las guerras, ni una incipiente industrialización alentada por la incorporación de la minería de Tarapacá, que dieron lugar al fortalecimiento de la organización y el mutualismo obrero, habían sido suficientes para conseguir cambios significativos en las condiciones de vida de los trabajadores y de los sectores más deprimidos. En contraste con el discurso higienista, buena parte de la población urbana seguía habitando en viviendas que contaban con pésimas condiciones en las primeras décadas del XX y «aferrada», como se denunciaba frecuentemente, a viejas maneras de paliar las enfermedades o, al menos, de suavizar sus efectos, ya que no de evitarlos. ${ }^{58}$

Las condiciones de vida no habían cambiado pero sí la percepción de «inhumanidad» de dichas condiciones, ya que a partir de la primera década del siglo XX el malestar se ve reflejado en el aumento de las movilizaciones obreras a pesar de la dureza con que fueron reprimidas. Entre las diferentes agrupaciones hubo coincidencia en la aceptación del discurso, pero aparecieron ciertas diferencias en torno a la intervención del Estado, como las mantenidas por algunas agrupaciones mutualistas y por los anarquistas. Illanes señala que los socialistas se pronunciaron, en un principio, a favor de la primera opción en su programa político de 1887 pero que eliminaron esta reivindicación cuando se reunificó el Partido Demócrata en 1894, ${ }^{59}$ para volver a introducirla nuevamente en las primeras décadas del XX.

Así, en la arena política la salud se convirtió en un arma arrojadiza cuando se asumió que la autogestión de la salud y de la higiene era un instrumento de poder y una manifestación más de la lucha de clases. Como señala Pávez, el policlínico de la IWW pretendía ser la demostración de que

57 Para el apoyo dado por las elites en las últimas décadas del XIX para «compensar» la debilidad de la acción del Estado en materia de apoyo, véase Ponce de León, 2011. Para otros países, y como medio de contención social, cfr. Arrom, 2011.

58 DeShazo, 2007, 117.

59 Illanes, 2003, 337. 
los obreros podían organizarse y gestionar su salud y su higiene sin necesidad de seguir «leyes leoninas dictadas por el gobierno», como señalaba la Hoja Sanitaria en $1925 .{ }^{60}$ Por otra parte, el discurso asumido de la higiene y la medicalización se convirtió en instrumento de control de la conducta de los trabajadores. ${ }^{61}$ La diferenciación a partir de la objetivación se constituyó, a su vez, en la manera de evitar la dominación por parte del Estado pero no la dominación en sí.

Por tanto, no siempre la aceptación de la salud, entendida como una necesidad e incluso como un derecho, estuvo acompañada de la idea de que fuera responsabilidad indelegable del Estado. Paralelamente a la autogestión y a la organización de mancomunales obreras, se fueron dando las primeras resistencias a que fueran los trabajadores quienes tuvieran sus propios recursos en cuanto a previsión y apareció entonces lo que María Angélica Illanes ha denominado «el ataque de la burguesía». ${ }^{62}$

La salud y la higiene quedaron bajo la responsabilidad del Estado a partir de la segunda década del siglo XX a pesar de las resistencias iniciales debido a la multiplicidad de actores que se implicaron en la difusión y la puesta en marcha de reformas. Su adopción significó la reformulación completa de la concepción del Estado.

\section{Consideraciones finales}

El higienismo establece una profunda relación entre conocimiento-poder-salud en la que el elemento modernizador está siempre presente. En aras de la modernidad y del progreso se imponen unas pautas de comportamiento público en materias de salud e higiene de las que no podrá sustraerse nadie que no quiera quedar al margen de la sociedad. Incluso la posibilidad de marginalidad será prácticamente nula debido a la persecución a que se vieron sometidos aquellos que no pudieron o no quisieron adoptar las nuevas pautas. En torno al tema se genera un lenguaje de control, ejemplarizante y segregacionista que se ve respaldado por el ejercicio de la fuerza, más o menos explícita, desde el aparato estatal. No es gratuito que las primeras Juntas de Beneficencia dependieran, en un principio, del Ministerio de

60 Pávez, 2009, 429.

61 Fuster, 2012, 188.

62 Illanes, 2003, 363. El establecimiento, por ley, de la obligación de pagar cuotas al Estado para la seguridad social dejó a los trabajadores sin posibilidades de autogestión, pues se convirtió en algo imposible separar de sus ya exiguos salarios, ahora despojados de la cuota oficial, una cantidad, así fuera mínima, para gestionar organismos autónomos de salud. 
Interior, o que los primeros códigos de conducta se conocieran como leyes de policía sanitaria. La salud, al ser pública, tomó tintes policiales antes que de apoyo y durante el período que nos ocupa fueron más frecuentes las acciones de persecución y crítica hacia quienes no tenían acceso, que las medidas para paliar las deficiencias en materia de higiene y salud. No obstante, desde finales del siglo y en torno a las fechas de celebración del centenario se fue fortaleciendo una postura reformista que tenía los mismos objetivos, sin bien era impulsada por diferentes motivaciones vinculadas a las diversas ideologías de sus impulsores (liberales, conservadores, católicos, obreros). Esta postura sembró las bases del Estado social.

Por otra parte, esta relación conocimiento-salud-poder tuvo tintes supranacionales y quedó vinculada estrechamente a la cuestión comercial desde el momento en que se insistió en el control fronterizo de los puertos y en la necesidad de mantener expeditos los caminos que posibilitan los flujos comerciales. A nivel estatal, acatar las directrices internacionales implicaba la posibilidad de mantener una posición en el mercado internacional, y no hacerlo se traducía en quedar fuera del circuito. La necesidad de no quedar al margen exigió la formulación de un discurso que reflexionaba permanentemente sobre los beneficios de estar dentro de ese mercado internacional como condición de la modernidad. Las comparaciones se realizaban predominantemente con aquellos países que sí cumplían la normativa y eran considerados líderes en «progreso», aquellos que, en definitiva, eran dignos de emulación y con los que, por otro lado, se establecían relaciones comerciales sustanciosas. Es así como se adopta un lenguaje de superación y de reflexión sobre los males que aquejan a Chile y se emiten las recetas para salir de la marginalidad económica a través de fórmulas vigorizantes para sanear a la sociedad y a los individuos como país y como raza. ${ }^{63}$

No podemos dejar de lado, no obstante, que en esos años tuvo lugar también el proceso de transformación del Estado; el paso de las «repúblicas epidérmicas» a las «repúblicas sustanciales». ${ }^{64}$ Chile no queda al margen de dicho proceso y por ello lanza su mirada hacia otros estados supuestamente exitosos. La comparación con los otros es inevitable y «casi enfermiza». ${ }^{65}$ Lo vemos permanentemente en las críticas y las propuestas de higienistas y reformistas, en las cifras de mortalidad, de víctimas de epidemias y en las estadísticas generales presentadas por Adolfo Murillo, Augusto Orrego, Pedro

63 Dichos discursos llegaron a defender posturas decididamente eugenésicas. Cfr. Leyton, 2015.

64 Aguirre y Mc Evoy, 2008.

65 Funes, 2014. 
Lautaro Ferrer, Juan Enrique Concha, etc. Todos ellos comparan permanentemente lo que está ocurriendo en Chile con lo que pasa en otros países. Esta crítica y estas comparaciones aumentan en torno a los festejos del centenario, cuando se presenta la oportunidad de reflexionar sobre el significado de las independencias y de la evolución de Chile como nación. La idea de país que se quiere dar para reafirmar la experiencia de cien años de vida independiente de cara al interior y al exterior, pone en evidencia los resultados de la relación entre ciencia y progreso y la posición que los diferentes grupos sociales ocupan en el esquema de la modernidad. Es en este contexto en el que las reformas aplicadas en las ciudades de acuerdo al modelo higienista pasaron por la destrucción de antiguos iconos coloniales como el puente de Cal y Canto en Santiago, el Morro do Castelo en Río de Janeiro, las obras de desecación y desagüe en la capital mexicana o el incendio provocado en el circo de Frank Brown en Buenos Aires. ${ }^{66}$ En Chile, la creación en 1887 del Ministerio de Industria y Obras Públicas supuso un hito en la evolución de la intervención del Estado en temas de urbanismo, si bien - al igual que sucedió con la Ley de Habitaciones Obreras de 1906-en principio tuvo un papel más reactivo que proactivo, si atendemos a las demoliciones de lugares considerados insalubres frente a la limitada cantidad de viviendas construidas. ${ }^{67}$

Frente a la imagen moderna y opulenta de las nuevas ciudades, se evidencia, no obstante, una crisis más grande que puso de manifiesto el descontento social frente a las oligarquías y su idea de progreso. La revolución mexicana señaló el fin de los gobiernos oligárquicos en toda América Latina y Chile no fue una excepción. El parlamentarismo se había demostrado ineficaz para hacer efectivas las reformas exigidas por el cientifismo positivista y por el higienismo, unas reformas que quedaron ligadas, inherentemente, a la cuestión social. La acción del positivismo no fue, sin embargo, en vano pues sobre las bases del cientifismo se apoyaron los reformistas y se dio paso al surgimiento del Estado social.

En el marco de los avances científicos y de la normatividad consensuada e internacionalizada en aras del favorecimiento del tráfico comercial y humano, la difusión del discurso fue exitosa. Fueron muy diversos los actores que se empeñaron en hacer llegar los lineamientos del nuevo paradigma higiénico sanitario a nivel internacional y nacional. La trasmisión de conocimientos se realizó de manera globalizada a partir de un heterogéneo grupo de actores agrupados en una «nebulosa reformista» constituida a partir de

66 Idem.

67 Millán-Millán, 2016. 
las contribuciones de médicos, higienistas, funcionarios públicos, políticos, ingenieros y contratistas que pusieron sus conocimientos y sus intereses en juego para difundir y poner en práctica las reformas necesarias para la transformación de las ciudades. Hemos señalado aquí la importancia de los congresos internacionales especializados, así como la relevancia que adquirió el tema en las exposiciones universales que se realizaron en las principales capitales a ambos lados del Atlántico. En ellas se puso en evidencia la magnitud del cambio y a partir de ellas los intelectuales y las elites participantes hicieron copartícipes de los cambios a sus conciudadanos. El nivel de intercambio de conocimientos y de especialistas fue importante. A partir de la segunda mitad del siglo XIX a Chile llegaron especialistas médicos y reformistas que contribuyeron a modificar la estructura de la enseñanza superior y que entraron a formar parte de las instituciones de salubridad e higiene que se crearon durante el período que nos ocupa. En esta labor de difusión, las escuelas tuvieron un papel importante como organismos encargados de divulgar los principios básicos de higiene y salud a los niños. Como parte de estas labores de difusión, también se realizaron campañas higiénicas para hacer llegar el discurso a todas partes del país. En estas campañas de difusión jugó un papel importante la prensa, sobre todo la prensa obrera.

En materia de difusión, la contribución de la intelligentsia obrera comienza a darse de manera sistemática en la primera década del siglo XX. A partir de finales del siglo XIX y, sobre todo, con la primera década del XX la cuestión de la salud y de la higiene se introdujo en el discurso, y después en las reivindicaciones, de las principales organizaciones obreras. Las agrupaciones obreras, en un principio, optaron por llevar el discurso a la práctica desde la autogestión, pero en torno a la celebración del centenario, y en el marco de la primera gran crisis del capitalismo que supuso la Primera Guerra Mundial, fueron incorporándolo en sus programas como una demanda a favor de la intervención del Estado de manera similar a como ocurrió en otras partes del mundo a partir de la primera década del XX.

La inicial reticencia de los trabajadores a dejar la salud en manos del Estado se diluye ante la posibilidad de que este deje de ser el refugio y el patrimonio de las oligarquías. Así, las demandas a favor de una salud pública se fueron integrando - en un proceso global que implicó al resto de los países occidentales - en el discurso de las diferentes agrupaciones obreras ${ }^{68}$ La excepción estuvo, como hemos visto, en la acción propuesta

68 Topalov, 2004. 
por la IWW en torno a la autogestión, que se prolongó durante la década de 1920, y en las acciones destinadas a la autoconstrucción de viviendas obreras. Como señala Devés, con anterioridad la cultura obrera se veía a sí misma «como diferente, pero deseando rescatar los verdaderos valores de la cultura dominante. Rescatar, realizar los valores del saber científico o de la democracia política y social traicionados por la oligarquía, se decía». ${ }^{69}$

La labor de difusión y de institucionalización realizada por médicos e higienistas que contaron con el apoyo estatal hizo posible la penetración del discurso en todos los sectores de la población. Los defensores de la cuestión social, tanto desde posiciones católicas como la de Concha Subercasseux, como desde las progresistas y laicas de Orrego Luco, contribuyeron a relacionar higiene y justicia social y a fortalecer la idea de la obligación de la intervención estatal en materia de salud e higiene. Si bien en las dos últimas décadas del XIX se adjudicaron a los sectores populares las principales resistencias a la aplicación de las reformas, percibimos un cambio importante en las primeras décadas del XX cuando los principales publicistas comienzan a interpelar a las elites como responsables de la ralentización de la puesta en marcha de las reformas. Las acusaciones perpetradas contra los grupos de poder que paralizaban las leyes cuando llegaban al parlamento, como ocurrió con la ley de vacunación obligatoria, o las denuncias en contra de los propietarios de los conventillos que evitaban las demoliciones al tiempo que eludían la realización de reformas de abastecimiento de agua y saneamiento, fueron paralelas a las exigencias para aumentar la participación estatal. En esta línea encontramos propuestas como la de Orrego Luco en torno a la implementación de impuestos directos sobre el capital para dotar a los municipios y al Estado de los recursos necesarios para finalizar el proceso de institucionalización y de reforma. Todo ello culminará, finalmente, con el fin del parlamentarismo (y con él, el del gobierno oligárquico), que dio paso a una nueva concepción del Estado que daría fin a la «cuestión social». El primer presidente en esta nueva etapa fue, precisamente, Arturo Alessandri, aquel que en 1923 pronunció el discurso a favor del fortalecimiento de las instituciones higiénicas en el país, lo cual, a nuestro juicio, constituye una manifestación palpable del cambio de dirección en la concepción de la organización del Estado.

Recibido el 17 de septiembre de 2015 Segunda versión el 18 de abril de 2016 Aceptado el 17 de mayo de 2016

69 Devés, 1991, 131. 


\section{Referencias bibliográficas}

Aguirre, Carlos y Mc Evoy, Carmen (eds.), Intelectuales y poder: ensayos en torno a la república de las letras en el Perú e Hispanoamérica (ss. XVI-XX), Lima, Instituto Francés de Estudios Andinos / Instituto Riva Agüero, 2008.

Arrom, Silvia, Para contener al pueblo: el Hospicio de Pobres de la Ciudad de México, 1774-1871, México, CIESAS, 2011.

Cabrera, María Josefina, «¿Obligar a vivir o resignarse a morir? Viruela y vacuna: el debate sobre una enfermedad y su prevención a comienzos del siglo XX en Chile», en Zárate, María Soledad (comp.), Por la salud del cuerpo. Historia y políticas sanitarias en Chile, Santiago, Ediciones Universidad Alberto Hurtado, 2008, 35-80.

Concha Subercasseux, Juan Enrique, Conferencias sobre economía social dictadas en la Universidad Católica de Santiago de Chile, Santiago, Imprenta Chile, 1918.

Dávila Boza, Ricardo, La higiene de la escuela, Santiago de Chile, Imprenta Cervantes, 1884.

DeShazo, Peter, Trabajadores urbanos y sindicatos en Chile: 1902-1927, Santiago de Chile, Centro de Investigaciones Diego Barros Arana, DIBAM, 2007.

Devés, Eduardo, «La cultura obrera ilustrada en tiempos del centenario», Mapocho. Revista de Humanidades y Ciencias Sociales, 30, Santiago, 1991, 127-136.

Durán, Manuel, «Discursos e imágenes sobre el cuerpo femenino en las teorías científicas e higienistas: Chile, siglos XIX y XX», en Cossío, Germán; Errázuriz, Rebeca; Lagos, Felipe y López, Natalia (eds.), Políticas culturales, discursos y poder en América Latina, Santiago, Universidad de Chile, 2009, 97-118.

Encina, Francisco A., Nuestra inferioridad económica. Sus causas, sus consecuencias, Santiago de Chile, Editorial Universitaria, 1955 [1. a ed. 1911].

Ferrer Rodríguez, Pedro Lautaro, Higiene y asistencia pública en Chile. V Conferencia Sanitaria Internacional Americana, Santiago, Imprenta, Litografía y Encuadernación Barcelona, 1911.

Folchi, Mauricio, «La higiene, la salubridad pública y el problema de la vivienda popular en Santiago de Chile, 1843-1925», en Loreto López, Rosalva (coord.), Perfiles habitacionales y condiciones ambientales. Historia urbana de Latinoamérica, siglos XVII-XX, Puebla, BUAP, 2007.

Foucault, Michel, El poder, una bestia magnífica. Sobre el poder, la prisión y la vida, Buenos Aires, Siglo XXI, 2012.

Funes, Patricia, Historia mínima de las ideas políticas en América Latina, Madrid, Turner, 2014.

Fuster Sánchez, Nicolás y Moscoso-Flores, Pedro, «La Hoja Sanitaria de la IWW y la medicalización de la organización obrera en Chile (1924-1927)», La Cañada, 3, Santiago, 2012, 181-200. 
Godoy Urzúa, Hernán, La Cultura Chilena, Santiago de Chile, Editorial Universitaria, 1982.

González Leandri, Ricardo, «Internacionalidad, higiene y Cuestión Social en Buenos Aires (1850-1910). Tres momentos históricos», Revista de Indias, 73, 257, Madrid, 2013a, 23-54.

González Leandri, Ricardo, «Miasmes cosmopolites. Circulation internationale de savoirs et de practiques d'Hygiene. Buenos Aires 1850-1870», en Pérez, Liliane y González Bernaldo de Quirós, Pilar (dirs.), Les savoirs-mondes. Mobilité et circulation des savoirs du Moyen Age an XXI siècle, Rennes, PUR, 2013b, 381-399.

Grez Toso, Sergio, La «cuestión social» en Chile. Ideas y debates precursores (1804-1902), Santiago de Chile, DIBAM, 1997.

Hevía, Patricio, «Los inicios de la Escuela de Salubridad de Chile: 1943-1957», Revista Chilena de Salud Pública, X-3, Santiago, 2006, 170-176.

Illanes, María Angélica, Chile (des)centrado. Formación sociocultural republicana y transición capitalista: 1880-1980, Santiago, LOM Ediciones, 2003.

Leyton, César; Palacios, Cristián y Sánchez, Marcelo (eds.), El bulevar de los pobres. Racismo científico, higiene y eugenesia en Chile e Iberoamérica, siglos XIX y XX, Santiago, Ocho Libros Editores, 2015.

Lezama, José Luis, La construcción social y política del medio ambiente, México, El Colegio de México, 2004.

López Gutiérrez, Osvaldo, Diccionario biográfico obrero de Chile, Santiago de Chile, Imprenta y Encuadernación Bellavista, 1912.

Martínez Moctezuma, Lucía, «El agua y los recursos naturales como representación en los libros de texto mexicanos, 1882-1920», Revista Mexicana de Investigación Educativa, 30, México, 2006, 847-866.

Mayer, Leticia, «Entre el "ciudadano" y el "hombre medio". Leyes, estadísticas, mortalidad e higiene en el siglo XIX», en Bustamante, Jesús; Giraudo, Laura y Mayer, Leticia (eds.), La novedad estadística. Cuantificar, cualificar y transformar las poblaciones en Europa y América Latina, siglos XIX y XX, Madrid, Ediciones Polifemo, 2014, 85-127.

Millán-Millán, Pablo, «Aplicación e impacto de la Ley de Habitaciones Obreras de 1906: el caso de Valparaíso (Chile)», Eure, 42, 125, Valparaíso, 2016, 273-293.

Molina Bustos, Carlos Antonio, Institucionalidad Sanitaria Chilena 1889-1989, Santiago de Chile, LOM Ediciones, 2010.

Molina, C. y Salamanca J. M., Agua potable y desagües y otros trabajos relativos a la higiene y la salubridad del pueblo. Memoria presentada al Consejo Departamental de Hijiene de Talca, Santiago, Imprenta La Libertad, 1894.

Morris, James, «Las élites, los intelectuales y el consenso», en Godoy, Hernán (ed.). Estructura social de Chile, Santiago, Editorial Los Andes, 2000. 
Murillo, Adolfo, Vacunación obligatoria. Discurso pronunciado en la Cámara de Diputados (sesión 6 de julio de 1883), Santiago, Imprenta de La República, 1883.

Murillo, Adolfo, La mortalidad urbana en Chile. Discurso leído en la sesión de apertura del Congreso Científico General Chileno celebrado en Concepción el 23 de febrero de 1896, Santiago, Imprenta y Encuadernación Roma, 1896.

Orrego Luco, Augusto, La cuestión social, Santiago, Imprenta Barcelona, s.f. [1884].

Palacios, Nicolás, Raza Chilena, Santiago de Chile, Editorial Chilena, 1918 [1. a ed. 1904].

Pávez, Fabián, «Experiencias autogestionarias en salud: El legado de Gandulfo en La Hoja Sanitaria y el Policlínico de la Organización Sindical Industrial Workers of the World (1923-1942)», Revista Médica de Chile, 137, 3, Santiago, 2009, 426-432.

Ponce de León, Macarena, Gobernar la pobreza. Prácticas de caridad y beneficencia en la ciudad de Santiago (1830-1890), Santiago, DIBAM, 2011.

Rengifo, Francisca, «Familia y escuela. Una historia social del proceso de escolarización nacional. Chile, 1860-1930», Historia, 45, 1, Santiago, 2012, 123-170.

Reyes Konings, Luis S., «La cuestión social en Chile: Concepto, problematización y explicación. Una propuesta de revisión historiográfica», Estudios Históricos, 5, Montevideo, 2010, http://www.estudioshistoricos.org/edicion5/ 0502Cuestion_Social_en_Chile.pdf [Consultado: 19/09/2016].

Riis, Jacob A., Cómo vive la otra mitad: estudios entre las casas de vecindad de Nueva York, Madrid, Alba Editorial, 2004 [1888].

Rodgers, Donald, Atlantic crossing: social politics in a progressive age, Cambridge, Harvard University Press, 1998.

Rodrigues Soares, Paulo R., «La difusión del higienismo en Brasil y el saneamiento de Pelotas (1880-1930)», Scripta Nova, 69, Barcelona, 2000, art. 38, http:// www.ub.edu/geocrit/sn-69-38.htm [Consultado: 10/04/2016].

Sánchez Andaur, Raúl y Simón Ruiz, Inmaculada, «Cambio de paradigma y primera empresa de agua en la ciudad de Talca (1870-1931)», Tiempo Histórico, 9, Santiago de Chile, 2015, 98-107.

Serrano, Sol; Ponce de León, Macarena y Rengifo, Francisca (eds.), Historia de la Educación en Chile (1810-2010). Tomo II. La educación nacional (18801930), Santiago de Chile, Taurus, 2012.

Simón Ruiz, Inmaculada, «La modernización del sistema de aguas en Talca», SudHistoria, VII, Valdivia, 2013,100-115.

Terrón Bañuelos, Aida, «La higiene escolar: un campo de conocimiento disputado», Areas. Revista internacional de Ciencias Sociales, 20, Murcia, 2000, 73-94.

Topalov, Christian, «De la "cuestión social" a los "problemas urbanos": los reformadores y la población de las metrópolis a principios del siglo $\mathrm{XX}$ », en 
Danani, Claudia (comp.), Política social y economía social. Debates fundamentales, Buenos Aires, UNGS / OSDE / Altamira, 2004, 41-71.

Urbina Carrasco, María Ximena, Los conventillos de Valparaíso, 1880-1920. Fisonomía y percepción de una vivienda popular urbana, Valparaíso, Ediciones Universitarias de Valparaíso, 2011.

Vial, Gonzalo, La sociedad chilena en el cambio de siglo (1891-1920), Santiago, Editorial Santillana del Pacífico, 1981.

Yáñez, Juan Carlos, La intervención social en Chile, 1907-1932, Santiago, RIL, 2008.

Zárate, María Soledad, Dar a luz en Chile, siglo XIX: de la «ciencia de hembra» a la ciencia obstétrica, Santiago, Centro de Investigaciones Diego Barros Arana, 2007.

Zárate C., María Soledad y Del Campo P., Andrea, «Curar, prevenir y asistir: Medicina y salud en la Historia de Chile», Nuevo Mundo Mundos Nuevos, 2014, https://nuevomundo.revues.org/66805 [Consultado: 10/04/2016]. 